\title{
Removal of Orange-G, Vat Yellow, Erythrosine Dyes from Synthetic Wastewater by Electrocoagulation and Nanofiltration
}

\author{
Uzoh FrancolinsChigozie* and NwabanneTagbo Joseph \\ Chemical Engineering Department, Faculty of Engineering,NnamdiAzikiwe University, P.M.B 5025 Awka, Anambra State, Nigeria
}

\begin{abstract}
Efficiency of electrocoagulation and nanofiltration in removing color from synthetic wastewater were investigated. Three representative dye molecules were selected for the synthetic dye wastewater:Azo dye (Orange-G dye), a synthetic dye (Erythrosine) and a Vat dye (Vat yellow). Iron electrode was use as a sacrificial anode in the study. The influence of electrolysis time, operating current density, initial $\mathrm{pH}$, initial dye concentration and temperature on process performances was investigated. Experiments were conducted to find the desired conditions for removal of particular concentration of the dyes. The results showed that $99.958 \%$ of Orange-G, $99.854 \%$ Of Erythrosine, $85.956 \%$ Vat yellow was decolorized for initial dye concentration of $100 \mathrm{mg} / \mathrm{l}$ with the current density of $1559 \mathrm{~A} / \mathrm{m}^{2}$, electrolysis time of 25 minute and initial $\mathrm{pH}$ of 10 . The electrochemical technique showed satisfactory color removal efficiency and reliable performance in treating the dye types. Electrode mass loss and energy consumed were also calculated.
\end{abstract}

Keywords: Nanofiltration; Electrocoagulation; Dye; Removal efficiency; Synthetic wastewater

Nomenclature: $\mathrm{Al}$ : Aluminium; $\mathrm{Al}(\mathrm{OH})_{3}$ : Aluminium Hydroxide; DC: Direct Current; EC: Electrochemical cell; Fe: iron; $\mathrm{Fe}(\mathrm{OH})_{3}$ : Iron Hydroxide; $\mathrm{HCl}$ : Hydrochloric Acid; $\mathrm{NaCl}$ : Sodium Chloride; $\mathrm{NaOH}$ : Sodium Hydroxide; rpm: Revolution Per Minutes; UV: Ultra Violet

\section{Introduction:}

Electrocoagulation is an alternative technology for wastewater treatment and recovery of valuable chemicals from wastewater. It is an electrochemical technique whereby anodes (aluminum or iron) corrode to release active coagulants into solution. The generated metallic ions, i.e. $\mathrm{Al}^{3+}(\mathrm{aq})$ and $\mathrm{Fe}^{3+}(\mathrm{aq})$, will undergo further spontaneous reactions to produce corresponding hydroxides and/or polyhydroxide [1]. These hydroxide/ polyhydroxide/ polydroxy metallic compounds have a strong affinity with dispersed/ dissolved molecules to cause coagulation/adsorption [1,2].

The technology for color removal can be divided into three categories: biological, chemical and physical [3]. All of them have advantages and drawbacks. The main advantages of electrocoagulation over other conventional techniques such as chemical coagulation and adsorption are in situ delivery of reactive agents, no generation of secondary pollution, and compact equipment. Many studies have reported the potentials of electrocoagulation in treating a variety of wastewater, including removing suspended solids $[4,5]$, removing dyes $[6,7]$, breaking oil emulsions in water [2].

Nanofiltration is a relatively recent membrane filtration process used most often with low total dissolved solids water such as surface water and fresh groundwater, with the purpose of softening (polyvalentcation removal) and removal of disinfection by-product precursors such as natural organic matter and synthetic organic matter. Nanofiltration is also becoming more widely used in food processing applications such as dairy, for simultaneous concentration and partial (monovalent ion) demineralization.

The textile industry consumes considerable amounts of water during dyeing and finishing operations. Dye-containing effluent is toxic to the environment since dyes are stable compounds, with low biodegradability and can be carcinogenic. Dyes are normally very large aromatic molecules consisting of many linked rings. Three common dyes, classified according to the fibers to which they can be applied and their chemical nature are: (1) acid dyes; (2) reactive dyes; (3) disperse dyes [6]. Acid dyes are water-soluble anionic compounds, applied from an acidic solution to nylon, wool, silk, and some modified acrylic textiles in an acidic medium. Acid dyes attach to fibers via hydrogen bonding, van der Waals forces and ionic bonding. Reactive dyes are water-soluble anionic compounds, mainly applied to cotton and rayon. Reactive dyes form covalent bonds with fibers. Disperse dyes are mostly used for oleophylic fibers and polyesters, and applied as a dispersion of finely ground powders. Typical textile effluent contains various types of dye molecules and might have fluctuating properties due to varying dyeing activities. Vat dyes are water insoluble compounds, generally based around anthriquinone or indigo. Excellent color fastness and UV stability is displayed and so these expensive dyes are often used for fabrics that must withstand frequent, harsh washing such as military uniforms and hospital textiles or those continuously exposed to daylight such as furnishings. However, dyeing activities of a factory can vary according to its customer's orders, resulting in different levels of dye types in wastewater. Therefore, the study of decolorization of mixed dyes is a necessary step toward the development of more effective treatments of textile wastewater and synthetic wastewater.

In this study, operational parameters were investigated that are suitable for treating synthetic wastewater containing an azo dye alone, a vat dye alone and synthetic dyes. These parameters included electrode type, electrode distance, current density, and electrocoagulation time. The effects of environmental factors, i.e. $\mathrm{pH}$ and temperature, on the process efficiency of the synthetic wastewater were also investigated.

*Corresponding author: Uzoh Francolins Chigozie,Chemical Engineering Department, Faculty of Engineering, NnamdiAzikiwe University, P.M.B 5025 Awka, Anambra State, Nigeria, E-mail: epio4real@yahoo.com

Received September 19, 2014; Accepted October 16, 2014; Published October 22, 2014

Citation: Chigozie UF, Joseph NT (2014) Removal of Orange-G, Vat Yellow, Erythrosine Dyes from Synthetic Wastewater by Electrocoagulation and Nanofiltration. J Adv Chem Eng 4: 112. doi: 10.4172/2090-4568.10001112

Copyright: (c) 2014 Chigozie UF, et al. This is an open-access article distributed under the terms of the Creative Commons Attribution License, which permits unrestricted use, distribution, and reproduction in any medium, provided the original author and source are credited. 
The filtration of the flocs was enhanced by Nano-Max50 nanofilter.

\section{Theory of Electrocoagulation}

In electrocoagulation process, the coagulants produced in situ have been discussed by a number of researchers as involving three stages:

1. Formation of coagulants by electrolytic oxidation of the sacrificial anodes.

2. Destabilization of the contaminants, particulate, suspension and breaking of emulsions.

\section{Aggregation of destabilized phases to form flocs.}

When potential is applied to the metal anodes, it causes two spate reactions:

1. $\mathrm{Fe} / \mathrm{Al}$ is dissolved from the anode generating corresponding metal ions which is almost immediately hydrolysed to polymeric iron or aluminium hydroxide. The polymeric hydroxide formed is an excellent coagulating agent. The consumable metal amides are used to continuously produce polymeric hydroxide in the vicinity of the anode. When these metal cations combine with the negative particles carried towards the anodes by electropheric motion, coagulation occurs.

2. Water is also electrolyzed in a parallel reaction producing bubbles of oxygen at the anode and hydrogen at the cathode. The bubbles attract the flocculated particles and through natural buoyancy floats to the surface. Destabilization mechanism of the contaminant, particulate suspension and breaking of emulsion from the other hand, has been described in broad steps and summarized as follows;

a. Compression of the diffused double layer around the charged species by the interaction of ions generated by oxidation of the sacrificial anodes.

b. Charge neutralization of ionic species present in wastewater by counter-ions produced by the electrochemical dissolution of the sacrificial anodes. These counter-ions reduce the electrostatic antiparticle repulsion to the extent that the Van der Waals' attraction predominates, thus, causing coagulation. A zero-net charge results in the process.

c. Flocs formation as a result of coagulation. This creates a sludge blanket which entraps and bridges the colloidal particles still remaining in the aqueous medium. The solid oxides, hydroxides and oxy-hydroxides provide active surfaces for the adsorption of the polluting species.

\section{Reactions at the electrode}

For a given electrochemical cell shown in Figure 1, set up is made up of metallic electrode, a potential difference is applied from an external DC power source, the anode undergoes oxidation by loss of electrons while the cathode, by reduction or deposition of elemental metal. The electrocoagulation reaction between metal " $\mathrm{M}$ " is summarized below.

\section{At the anode:}

$$
\begin{aligned}
& \mathrm{M}_{(\mathrm{s})}+\mathrm{ne}^{-} \quad \mathrm{M}_{(\mathrm{aq})}^{\mathrm{n+}} \\
& 2 \mathrm{H}_{2} \mathrm{O}_{(\mathrm{l})}+4 \mathrm{e}^{-} \quad 4 \mathrm{H}^{+}{ }_{(\mathrm{aq})}+\mathrm{O}_{2(\mathrm{~g})} \\
& \mathrm{Al}_{(\mathrm{s})} \quad \mathrm{Al}^{3+}{ }_{(\mathrm{aq})}+3 \mathrm{e}^{-}(\text {for aluminium electrode }) \\
& \mathrm{Fe}_{(\mathrm{s})} \quad \mathrm{Fe}_{(\mathrm{aq})}^{2+}+2 \mathrm{e}^{-}(\text {for iron electrode })
\end{aligned}
$$

\section{At the cathode:}

$\mathrm{M}^{\mathrm{n}+}{ }_{(\mathrm{aq})}+\mathrm{ne}$ $\mathrm{M}(\mathrm{s})$

$$
2 \mathrm{H}_{2} \mathrm{O}_{(1)}+2 \mathrm{e}^{-} \quad \mathrm{H}_{2(\mathrm{~g})}+2 \mathrm{OH}^{-}
$$

Depending on the $\mathrm{pH}$ of the aqueous medium, the $\mathrm{Al}^{3+}$ ions or $\mathrm{Fe}^{2+}$ ions generated undergoes hydrolysis producing complexes. These hydroxides, polyhydroxides, polyhydroxy metallic compounds have strong affinities for dispersed particles as well as counter ions to cause coagulation.

These gases evolved at the electrode (bubbles of hydrogen and oxygen at the cathode and anode respectively) impinge on and causes flotation of the coagulated materials.

The different electrode materials had an effect on the effectiveness of water treatment because of its mechanisms.

\section{Aluminium:}

Aluminium upon oxidation in an electrolytic system produces aluminium hydroxide, $\mathrm{Al}(\mathrm{OH}) \mathrm{n}$, where $\mathrm{n}=2$ or 3

Anode:

$2 \mathrm{Al}(\mathrm{s})$

$$
2 \mathrm{Al}^{3+}(\mathrm{aq})+6 \mathrm{e}-
$$

$2 \mathrm{Al}^{3+}(\mathrm{aq})+6 \mathrm{H}_{2} \mathrm{O}(\mathrm{l})$

$$
2 \mathrm{Al}(\mathrm{OH})_{3}(\mathrm{~s})+6 \mathrm{H}^{+}(\mathrm{aq})
$$

Cathode:

$6 \mathrm{H}^{+}(\mathrm{aq})+6 \mathrm{e}^{-}$ $3 \mathrm{H}_{2}(\mathrm{~g})$

Overall reaction:

$2 \mathrm{Al}+6 \mathrm{H}_{2} \mathrm{O}(\mathrm{l})$ $2 \mathrm{Al}(\mathrm{OH})_{3}(\mathrm{~s})+3 \mathrm{H}_{2}(\mathrm{~g})$

Iron:

Iron upon oxidation in an electrolytic system produces iron hydroxide, $\mathrm{Fe}(\mathrm{OH}) \mathrm{n}$ where $\mathrm{n}=2$ or 3 .

Two mechanism has been proposed for the production of $\mathrm{Fe}(\mathrm{OH}) \mathrm{n}$.

Mechanism 1: (Anodic medium)

Anode:

$4 \mathrm{Fe}(\mathrm{s}) \quad 4 \mathrm{Fe}^{2+}(\mathrm{aq})+8 \mathrm{e}-$

$4 \mathrm{Fe}^{2+}(\mathrm{aq})+10 \mathrm{H}_{2} \mathrm{O}(\mathrm{l})+\mathrm{O}_{2}(\mathrm{~g})$ $4 \mathrm{Fe}(\mathrm{OH})_{3}(\mathrm{~s})+8 \mathrm{H}^{+}(\mathrm{aq})$

Cathode:

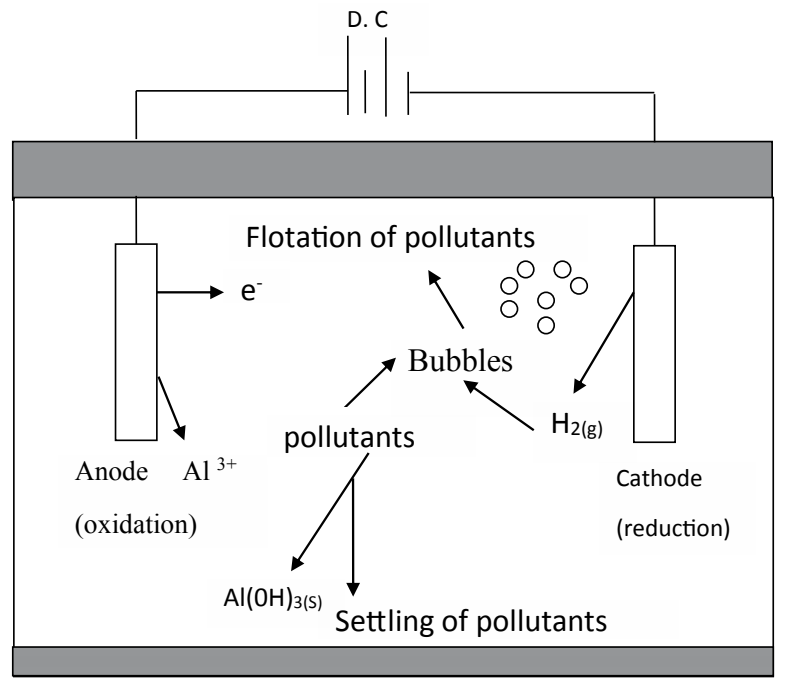

Figure 1: Schematic Diagram of EC Cell 
$8 \mathrm{H}^{+}(\mathrm{aq})+8 \mathrm{e}^{-}$

$4 \mathrm{H}_{2}(\mathrm{~g})$

Overall:

$4 \mathrm{Fe}(\mathrm{s})+10 \mathrm{H}_{2} \mathrm{O}(\mathrm{l})+\mathrm{O}_{2}(\mathrm{~g})$

$4 \mathrm{Fe}(\mathrm{OH})_{3}(\mathrm{~s})+4 \mathrm{H}_{2}(\mathrm{~g})$

Mechanism 2:

Anode:

$\mathrm{Fe}(\mathrm{s}) \quad \mathrm{Fe}^{2+}(\mathrm{aq})+8 \mathrm{e}^{-}$
$\mathrm{Fe}^{2+}(\mathrm{aq})+2 \mathrm{OH}^{-}(\mathrm{aq}) \quad \mathrm{Fe}(\mathrm{OH})_{2}(\mathrm{~s})$
Cathode:

$2 \mathrm{H}_{2} \mathrm{O}(\mathrm{l})+2 \mathrm{e}$

$\mathrm{H}_{2}(\mathrm{~g})+2 \mathrm{OH}^{-}(\mathrm{aq})$

Overall:

$\mathrm{Fe}(\mathrm{s})+2 \mathrm{H}_{2} \mathrm{O}(\mathrm{l})$

$$
4 \mathrm{Fe}(\mathrm{OH})_{3}(\mathrm{~s})+4 \mathrm{H}_{2}(\mathrm{~g})
$$

\section{Materials and Methods}

The Electrocoagulation unit consists of a cylindrical glass cell as shown in figure 2 , in which the anode and cathode electrode made of Iron were fixed at a distance of $5.7 \mathrm{~cm}$ from each other, a direct current power supply, a magnetic stirrer, and a synthetic wastewater. A Laboratory model DC power supply apparatus (HUPE Model LN003C) was used to maintain constant DC current. A multimeter (ALDA DT-830D) was used to measure current and voltage. UV spectrophotometer was use to check the concentration of the dyes. The synthetic wastewater stock solution was prepared by dissolving $0.5 \mathrm{~g}$ of each dyes (Orange-G, Vat yellow and Erythrosine) in $1 \mathrm{dm}^{3}$ of distilled water, of which the working solution was taking from it at different concentrations (500 mg/l, $300 \mathrm{mg} / \mathrm{l}, 200 \mathrm{mg} / \mathrm{l}, 100 \mathrm{mg} / \mathrm{l}$ and $50 \mathrm{mg} / \mathrm{l}$ ) $\mathrm{HCl}$ and $\mathrm{NaOH}$ (Merck), $\mathrm{NaCl}$ (Aldrich) were used.

The electrocoagulation cell had a working volume of $250 \mathrm{ml}$, considering the dimensions of the electrodes as well as their submergence depth; this provides an electrode area to volume ratio of $5.1 \times 10^{-6} \mathrm{~m}^{2} /$ $\mathrm{m}^{3}$ in the reactor. The direct current was supplied by a laboratory model power supply instrument in which the current density could be regulated at a given level. Appropriate dosage of current was added to $250 \mathrm{ml}$ of synthetic dyes. The suspension, charged with $\mathrm{NaCl}$ solution by adding $5 \mathrm{ml}$ drops, the $\mathrm{pH}$ is tuned to range 3-10 by adding $\mathrm{HCl} /$ $\mathrm{NaOH}$. All runs were performed at $150 \mathrm{rpm}$, followed by 15 minutes of settling. Nano-Max50 (a heavy duty, two axis nanopositioning stage designed to carry heavy experimental assemblies) was used as nanofilter. The nanofiltrate samples were measured using the visible spectrometer. A calibration curve for various dyes and corresponding concentration were made to enable determination of final conc. Ce, prior to startino

$R_{E}{ }^{\mathrm{Co}-\mathrm{Ce} / \mathrm{Co}} \times 100$

Co $=$ Initial concentration before coagulation.

$\mathrm{Ce}=$ Final concentration after coagulation

$\mathrm{R}_{\mathrm{E}}=$ Percentage removal efficiency.

Before each run, electrodes were washed with acetone to remove surface grease, and then washed thoroughly with distilled water to remove any solid residues on the surfaces, dried. Typical runs were conducted at $303 \mathrm{~K}$, but some runs were conducted at $308 \mathrm{~K}, 313 \mathrm{~K}$, $318 \mathrm{~K}$ and $323 \mathrm{~K}$ in order to study the effect of temperature.

Electrical energy consumption and current efficiency are very important economical parameters in Electrocoagulation process and it was calculated using the commonly used equation.
$E=U I T$

Where;

$\mathrm{E}=$ Electrical energy $(\mathrm{Kwh}) / \mathrm{kg}$ dye removed.

$\mathrm{U}=$ Cell voltage in volt $(\mathrm{v})$.

$\mathrm{I}=$ Current $(\mathrm{A})$.

$\mathrm{T}=$ Electrocoagulation time (s).

Optimized current density percentage removal and energy consumption was evaluated using.

$$
\Theta=M_{\exp } / M_{\text {theo }} x 100
$$

The calculation was based on $_{M_{\text {mpm }}}$ ) omparison of experimental weight loss of Iron electrodes ( $M_{\exp }$ during $c^{1} m^{n+m}$ zoagulation process with theoretical amount of iron dissolution $\left(M_{\text {theo }}\right)$ according to Faraday's law.

$M_{\text {theo }}=$ MIT $/ n F m$

where; $\mathrm{M}=$ Molecular weight of Iron $(\mathrm{g} / \mathrm{mol})$,

$\mathrm{n}=$ Moles of electron,

$\mathrm{F}=$ Faraday's constant $(\mathrm{F}=96500 \mathrm{C} / \mathrm{Mol})$

\section{Results and Discussion}

\section{Electrode Mass Loss and Energy Consumption}

The result shows that an increase in the current density causes an increase in color removal efficiency (Figure 3). It also increases energy consumption. The electrical energy consumed was $0.033332 \mathrm{Kwh} /$ $\mathrm{m}^{3}$ while electrode mass loss was $0.0034823 \mathrm{~g} / \mathrm{m}^{3}$

\section{Effect of process parameters}

The electrocoagulation process is affected by several operating parameters such as initial $\mathrm{pH}$, initial concentration of dye, current density, electrocoagulation time and temperature. In this work, all these effects have been evaluated to obtain an optimum removal of various dyes in synthetic wastewater.

\section{Effect of initial $\mathbf{p H}$}

It has been recognized that $\mathrm{pH}$ has a considerable effect on the efficiency of the electrocoagulation process. This change depends on the type of electrode material, initial $\mathrm{pH}$ of the treated solution. In addition, $\mathrm{pH}$ measurements were found to be very important in showing the type of dominant reaction at the anode and cathode electrodes [8]. To examine its effect, the dye solutions were adjusted to the desired $\mathrm{pH}$ for each experiment by adding sodium hydroxide or hydrochloric acid solution.

The dye removal efficiency as a function of $\mathrm{pH}$, is shown in figure 4 for the initial dye concentrations of $100 \mathrm{mg} / \mathrm{l}$, current dosage of 1.5 ampere and a charging time of 25 minutes of operation. It can be seen that the initial $\mathrm{pH}$ has a significant effect on the dyes i.e. Orange- $\mathrm{G}, \mathrm{Vat}$ yellow and Erythrosine removal efficiency. There is minimum removal efficiency at acidic $\mathrm{pH}$. Close examination of the removal efficiency versus $\mathrm{pH}$ clearly indicates that the removal efficiency increase with $\mathrm{pH}$ [9]. From figure 4 it was seen that for $100 \mathrm{mg} / \mathrm{l}$ of dye solutions the removal is $96.234 \%$ for Orange-G dye, $96.447 \%$ for erythrosine dye and $83 \%$ for vat yellow dye at a $\mathrm{pH}$ of 10 and remains unaltered thereafter.

This is in accordance with [10], which investigated the removal of crystal violet by electrocoagulation. The result shows that for 100 


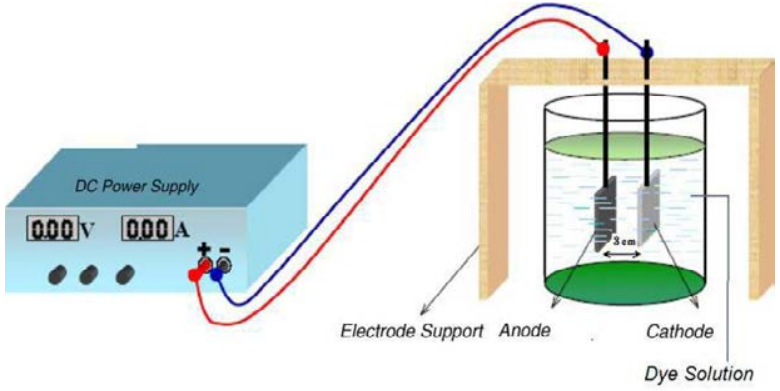

Figure 2: Experimental set-up

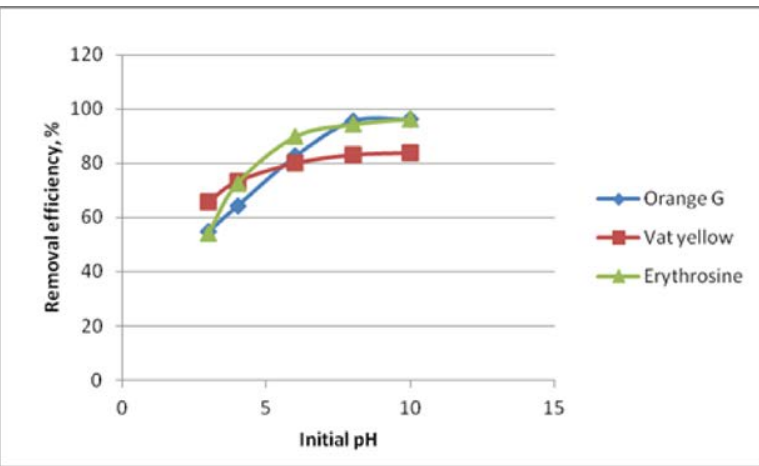

Figure 3: Effect of current density on Orange-G, Vat yellow, and Erythrosine dyes at temperature $=303 \mathrm{k}$, dye concentrations $=100 \mathrm{mg} / \mathrm{l}$, electrode area $=30.74 \mathrm{~cm} 2$, charge time $=15 \mathrm{~min}$., stirring speed $=150 \mathrm{rpm}, \mathrm{pH}=10$.

$\mathrm{mg} / \mathrm{L}$ of dye solution the removal is almost $100 \%$ at a $\mathrm{pH}$ of 8.5 and remains unaltered thereafter. Therefore, the desired $\mathrm{pH}$ of crystal violet degradation by EC process should be 8.5 . Since hydroxide ions, which are generated at the cathode, are neutralized by $\mathrm{H}^{+}$ions, sufficient amount of ferrous hydroxide complexes are not formed at this $\mathrm{pH}$. At basic $\mathrm{pH}$, dye removal efficiency is increased as number concentration of $\mathrm{OH}$ ion increases which help in formation of different ferrous hydroxide complexes.

\section{Effect of initial dye concentration}

Initial dye concentration plays an important role in the decolorization process using electrocoagulation. Therefore, the decolorization treatments of Orange-G, Vat yellow and Erythrosine dyes with different initial concentrations ranging from $50 \mathrm{mg} / \mathrm{l}$ to 500 $\mathrm{mg} / \mathrm{l}$ at a current dosage of 1.5 ampere were investigated. Figure 5 reveals the decolorization performance in terms of percentage removal as a function time of which a constant charge time of 25 minutes were used for the dyes. From the figure it was seen that the lower the dye concentration better would be the removal efficiency. It was also seen that concentration of $50 \mathrm{mg} / \mathrm{l}$ has the highest removal efficiency of $85.038 \%$ for orange-G, $80 \%$ for vat yellow and $96.447 \%$ for erythrosine dye. According to other researchers, dye solutions with different initial concentrations in the range of $20-60 \mathrm{mg} / \mathrm{l}$ in an optimized current density and time of electrolysis values. According to the result, as dye concentration increases the color removal percent decrease, because in constant condition, production of flocs and adsorption of dye to them is constant value. Up to the $9 \mathrm{~min}$, in all of concentrations the adsorption capacity of flocs was not exhausted and because of desorption of dye to solution, color removal decrease, especially in higher concentrations. The result showed that at $50 \mathrm{mg} / \mathrm{l}$ the removal efficiency was $83 \%$ which is the most effective removal [11]. In his study on comparison of iron and aluminium electrode in the treatment of blue Ca dye effluent using electrocoagulation, investigated the effects of dye initial concentration on the electrocoagulation process. Different dye concentrations, in the range of $0.01-0.05 \%$ of 1 litre, were tested under with different and constant current intensity. The result shows that increasing initial dye concentration results in decreasing removal efficiency. In fact, when the initial concentration varied from 0.01 to $0.02 \%$ of $1 \mathrm{~L}$, the removal percentage was, for example, $51.6 \%$ and $28.44 \%$ respectively, for $60 \mathrm{~mA}$ current density.

\section{Effect of current density}

It has been established that current density determines the coagulant production rate which influences the pollutant treatment by the electrocoagulation process [11]. Current density combines the effect of cell current and effective surface area of electrode. Current density during electrocoagulation experiment were varied by changing cell current and as well as electrode. Figure 3 shows the effect of current density on EC at constant electrode surface area $\left(30.74 \mathrm{~cm}_{2}\right)$. Each of this experiment was conducted with same initial concentration of 100 $\mathrm{mg} / \mathrm{l}$ of Orange-G, Vat yellow and Erythrosine dyes. After 25 minutes of charging time, the effective removal for the dyes by electrocoagulation is observed at higher current density. At higher current density, higher dissolution of electrode material (Faraday's law) with high rate of formation of monomeric and/ or polymeric iron hydroxides result in significant improvement in the dyes removal mainly due to coprecipitation forming solid solution like species, thereby generating

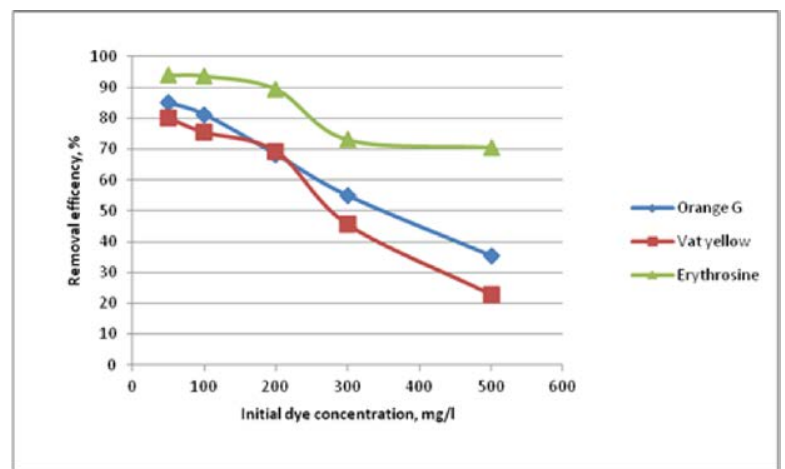

Figure 4: Effect of initial $\mathrm{pH}$ on Orange-G, Vat yellow, and Erythrosine dye at Dye concentrations $=100 \mathrm{mg} / \mathrm{l}, \mathrm{Temp}=303 \mathrm{k}$, current dosage $=1.5 \mathrm{~A}$, charge time $=15$ minutes, stirring speed $=150 \mathrm{rpm}$.

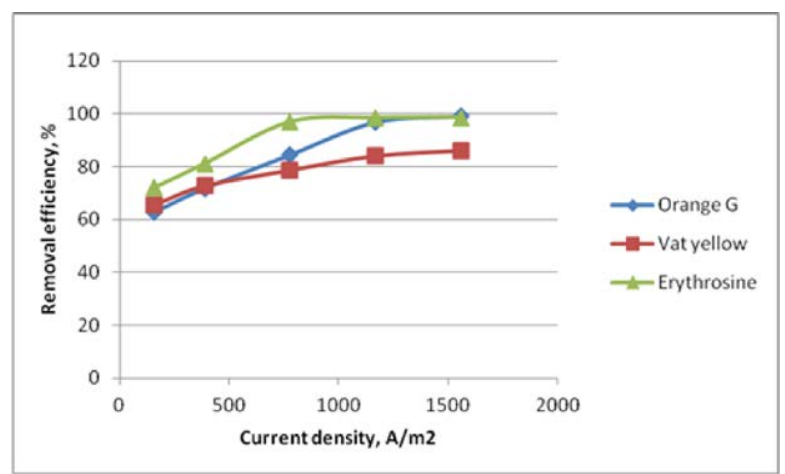

Figure 5: Effect of initial concentration on Orange-G, Vat yellow and Erythrosine dyes at temp. $=303 \mathrm{k}$, current dosage $=1.5 \mathrm{~A}$, charge time $=15 \mathrm{~min}$, stirring speed $=150 \mathrm{rpm}$. 


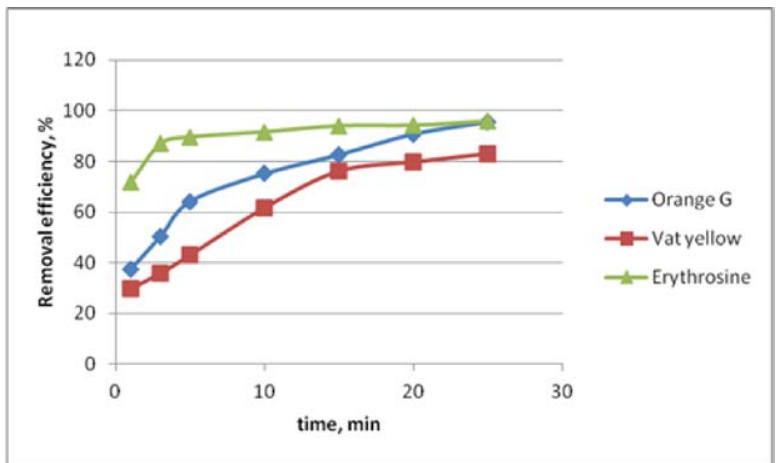

Figure 6: Effect of electrocoagulation time on Orange-G, Vat yellow and Erythrosine dyes; temperature $=303 \mathrm{k}$, dyes concentrations $=100 \mathrm{mg} / \mathrm{l}$, current dosage $=1.5$ ampere, stirring speed $=150 \mathrm{rpm}$.

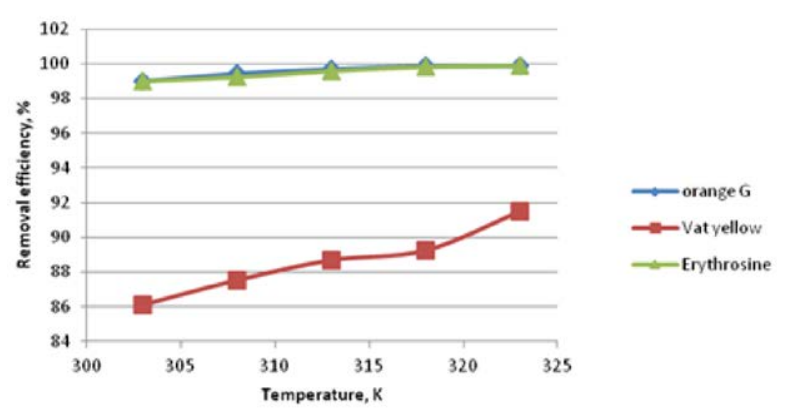

Figure 7: Effect of temperature on Orange-G dye, Vat yellow dye and Erythrosine dye, at an effective current dosage $=2.0 \mathrm{~A}$, effective charge time $=25 \mathrm{~min}$, concentration $=100 \mathrm{mg} / \mathrm{l}, \mathrm{pH}=10$, and stirring speed $=150 \mathrm{rpm}$

more sludge this boost removal rate [8]. From figure 6 it was seen that effective removal was at high current density with $98.958 \%$ removal for orange-G, $85.956 \%$ removal for Vat yellow and 98.54\% removal for erythrosine dye.

\section{Effect of electrocoagulation time}

Reaction time influences the treatment efficiency of the electrolytic process. During electrolysis, anodic electro-dissolution led to the release of coagulating species. The dye removal efficiency depends directly on the concentration of metal ions produced on the electrode. When the electrolysis time is increased, the concentration of metal ions and their hydroxide flocs increase. The electrolysis time effect color removal significantly, illustrated the removal of color as a function of electrolysis time. The effect of time of electrocoagulation was studied at constant current density of $\left(1169 \mathrm{~A} / \mathrm{m}^{2}\right)$. As shown in figure 6 for $100 \mathrm{mg} / \mathrm{l}$ of concentrations of the dyes (Orange-G, Vat yellow and Erythrosine dye). An increase in the time of electrocoagulation from 1 to $25 \mathrm{~min}$ yields an increase in the dye removal efficiency from $6 \%$ to 99\%.It is seen that increasing the charging time will lead to an increase in the removal efficiency up to $95.483 \%$ for orange-G dye, $82.855 \%$ vat yellow and $95.84 \%$ erythrosine at a constant current of 1.5 ampere.

\section{Effect of temperature}

Research on the effect of temperature on EC shows that, the current efficiency increases with an increase in temperature, until it reaches about $60^{\circ} \mathrm{C}$ where a maximum was found [12]. Further increase in temperature decreases the efficiency of the electrocoagulation process. The increase in temperature results in passivation of the electrode surface. Therefore, the decolorization treatments of Orange-G, Vat yellow and Erythrosine dyes with different temperature, 303k, 308k, $313 \mathrm{k}, 318 \mathrm{k}, 323 \mathrm{k}$ at an effective current dosage of 2.0 ampere were investigated. Figure 7 reveals the decolorization performance in terms of percentage removal as a function time of which a constant charge time of 25 minutes were used for the dyes. From the figure it was seen that the higher the temperature the better would be the removal efficiency. It was also seen that an increase in temperature from $303 \mathrm{~K}$ to $323 \mathrm{~K}$ yields an increase in dye removal efficiency of $91 \%$ to $99.9 \%$ for the dyes.

\section{Conclusion}

The decolorization of dye solution by this electrochemical process was affected by initial dye concentration, electrolysis time, initial $\mathrm{pH}$, current density and temperature. Ten iron electrodes with an effective area of were $5.1 \times 10^{-6} \mathrm{~m}^{2} / \mathrm{m}^{3}$ in the reactor optimized at a voltage of $2.0 \mathrm{~V}$ with an operating current density of $1562.5 \mathrm{~A} / \mathrm{mm}^{2}$. The results showed that current density was the most effective parameter with removal efficiency up to $99 \%$ for the different dyes. It was seen that with an increase in initial concentration of $50-500 \mathrm{mg} / \mathrm{l}$ color removal efficiency decreased remarkably. Therefore, initial concentration greatly affects the color removal efficiency. Effect of temperature seemed to be negligible. The electrocoagulation setup described in this study is simple in design and operation and can be used as a convenient tool in the removal of dyes from synthetic waste water.

\section{References}

1. Daneshvar N, Oladegaragoze A, Djafarzadeh N (2006) Decolorization of Basic Dye Solutions by Electrocoagulation: an investigation of the effect of operational parameters. Journal of Hazardous Materials 129: 116-122.

2. Canizares P, Carmona M, Lobato J, Martinez F, Rodrigo MA (2005) Electrodissolution of aluminum electrodes in electrocoagulation processes. Industrial and Engineering Chemistry Research 44: 4178-4185.

3. Robinson T, Chandran B, Nigam P (2002) Removal of dyes from a synthetic textile dye effluent by biosorption on apple pomace and wheat straw. Water Res 36: 2824-2830.

4. Abuzaid NS, Bukhari AA, Al-Hamouz ZM (1998) Removal of bentonite causing turbidity by electrocoagulation. Journal of environmental science and health 33: $1341-1358$.

5. Bukhari A (2008) Investigation of the electro-coagulation treatment process for the removal of total suspended solids and turbidity from municipal waste water. Bioresour Technol 99: 914-921.

6. Yang CL, McGarrahan J (2005) Electrochemical coagulation for textile effluent decolorization. J Hazard Mater 127: 40-47.

7. Aleboyeh A, Daneshvar N, Kasiri MB, (2008) Optimization of C.I. acid red 14 azo dye removal by electrocoagulation batch process with response surface methodology. Chem Eng Process 47: 827-832.

8. Holt P, Barton G, Mitchel C (2006) Electrocoagulation as a wastewater treatment. The third Annual Australian Environmental Engineering Research Event 1: $23-26$

9. Rajeshwar K, Ibanez JG, Swain GM (1994) Electrochemistry and the environment. J Appl Electrochem 24: 1077-1091.

10. Ghosh D, Medhi CR, Solanki H, Purkait MK (2008) Decolorization of crystal violet solution by electrocoagulation. Journal of Environmental Protection Science 2: 25-35.

11. Vinodha S, Babithesh S, Jegathambal P (2012) An Experimental Investigation on the Effect of The Operating Parameters For The Decolourisation Of Textile Waste Water By Electro Coagulation Process. International Journal of Engineering Research and Development 5: 45-54.

12. Chen GH, Chen XM, Yue PL (2000) Electrocoagulation and electroflotation of restaurant waste water. Journal of Environ Eng 126:858 - 863. 